\title{
Effect of an Education Program on Improving Help-Seeking among Parents of Junior and Senior High School Students in Japan
}

\author{
Hatsumi Yoshii \\ School of Health Sciences, Faculty of Medicine \\ Niigata University, Niigata, Japan \\ Tel: 81-252-272-264 E-mail: yoshii@clg.niigata-u.ac.jp
}

Yuichiro Watanabe

Department of Psychiatry, Niigata University Graduate School of Medical and Dental Sciences

Health Administration Center, Headquarters for Health Administration

Niigata University, Niigata, Japan

Tel: 81-252-272-213 E-mail: yuichiro@med.niigata-u.ac.jp

Hideaki Kitamura

Department of Psychiatry

Niigata University Graduate School of Medical and Dental Sciences

Niigata, Japan

Tel: 81-252-272-213 E-mail: kitamura@med.niigata-u.ac.jp

\begin{abstract}
Zhang Nan
Department of Medical Informatics and Statistics

Niigata University Graduate School of Medicine, Niigata, Japan

Tel: 81-252-272-471 E-mail: zhangnan@med.niigata-u.ac.jp

Kouhei Akazawa

Department of Medical Informatics and Statistics

Niigata University Graduate School of Medicine, Niigata, Japan

Tel: 81-252-272-471_E-mail: akazawa@med.niigata-u.ac.jp
\end{abstract}

Received: November 9, 2011 Accepted: November 23, $2011 \quad$ Published: January 1, 2012

doi:10.5539/gjhs.v4n1p33 URL: http://dx.doi.org/10.5539/gjhs.v4n1p33

\begin{abstract}
Early intervention in schizophrenia is important for patient prognosis and quality of life. At the time of the first episode, quality of life is influenced by identification of symptoms and by medical help-seeking behavior. In this prospective cohort study, we investigated help-seeking among 2690 parents of junior and senior high school students before and after the parents viewed a newly developed web-based education program aimed at improving knowledge of schizophrenia. Our web-based education program aimed to improve understanding of schizophrenia, including promotion of help-seeking. Many parents $(33.1 \%-50.0 \%)$ consulted a physician in a department of psychosomatic medicine when their child experienced symptoms. Characteristics that predicted a decision not to seek psychiatric medical help were having child with all symptoms, younger parent age, and lower family income $(\mathrm{p}<0.05)$. After the education program, the rate of parents who sought medical help within
\end{abstract}


1 week was significantly higher for all symptom categories except sleeplessness $(p=0.001)$. These findings suggest that the present web-based education program was useful in promoting medical help-seeking behavior among parents of junior and senior high school students in Japan.

Keywords: Help-seeking, Parents, Education program, Schizophrenia

\section{Introduction}

Early intervention in schizophrenia is important for patient prognosis and quality of life (QOL). Another reason for rapidly beginning treatment is that longer duration of untreated psychosis (DUP) is associated with lower long-term treatment effectiveness (Van et al., 2005). Thus, early intervention might improve response to antipsychotic treatment and long-term outcome (Perkins et al., 2005). Loebel et al. (1992) reported that duration of symptoms before treatment was significantly associated with time to remission and level of remission, i.e., longer duration predicted longer time to remission and lesser extent of remission. Longer DUP is associated with mental anguish, declines in QOL and social functioning, and poor clinical outcomes (Bechard-Evans et al., 2007). The average DUP was reported to be between 1 and 2 years (Larsen et al., 1998). Reducing DUP is an important challenge for mental health professionals, as it influences patient prognosis (Chong et al., 2004). In a review by Kessler et al. (2005), the authors noted that one-half of cases of mental illness begin by age 14 years and that three-fourths begin by age 24 years. In addition, they found evidence of delays in help-seeking among young people with emerging psychosis (Lincoln et al., 1995; Bechard- Evans et al., 2007). Bechard-Evans et al. (2007) showed that adolescents show poor social and academic adjustment and are socially withdrawn. Furthermore, their changes in behavior are more likely to go undetected when psychosis begins. Therefore, they are less likely to be brought to a mental health professional for help. These findings show that rapid detection of the initial onset of psychosis is important in young people because it would permit treatment to start earlier. However, young patients who are severely mentally ill have few mental health consultations (Nishida et al., 2008), and young people who need treatment frequently do not seek help (Boydell et al., 2006). Therefore, psychiatric outcomes among young patients might depend on whether their parents can understand the symptoms of mental illness and seek appropriate medical care at an early stage (Helgason, 1990; Perkins et al., 2005).

In recent years, there have been a number of studies of help-seeking (Platz et al., 2006; Unal et al., 2007; Compton et al., 2008; O'Callaghan et al., 2010). However, there has been no such study among the parents of junior and senior high school students. In this prospective cohort study, we (1) assessed help-seeking among parents when junior and senior high school students have schizophrenia symptoms or prodromal and nonspecific symptoms of schizophrenia, (2) identified factors associated with failure to seek medical help, and (3) investigated the effectiveness of a newly developed web-based education program that aimed to improve understanding of schizophrenia, including the promotion of help-seeking.

\section{Methods}

\subsection{Participants}

The participants were 2690 parents of junior and senior high school students. They were extracted from candidates in a large database administered by a private Japanese company that specializes in questionnaire research. Gender and region were used as variables for stratified random sampling. Consent was obtained from all participants by the same company that administered the database. All participants completed a questionnaire on an internet website administered by the survey company. The details have been previously described (Yoshii et al., 2011). This study was approved by the Ethics Committee of the Niigata University School of Medicine.

\subsection{Questionnaire}

The questionnaire used in the present study consisted of 3 sections. Section 1 collected demographic information on respondents. Section 2 asked about consultations their child had for a symptom of schizophrenia, a prodromal symptom, and nonspecific symptoms of schizophrenia. The participants were then asked to indicate all types of consultations they had sought from among 15 choices (e.g., family circle, homeroom teacher, psychiatric clinic, health center) for a child with sleeplessness (nonspecific symptom of schizophrenia), social withdrawal (prodromal symptom), strange behavior (symptom of schizophrenia), or all 3 symptoms. In section 3 , the participants were requested to select from 5 items regarding the timing of the consultation with regard to onset of symptoms (within 1 week, about 1 month later, about half a year later, more than 1 year later, treatment not needed) when their child had the above symptoms (the first questionnaire). All participants then viewed the education program. One week later, the questionnaire was answered again (the second questionnaire), and the effectiveness of the education program was evaluated among the participants. 


\subsection{Web-based education program}

After completing the first questionnaire survey, all respondents were invited to view a web-based education program that aimed to improve understanding of schizophrenia, including promotion of help-seeking. This program was developed by the authors (Yoshii et al., 2011). The content included help-seeking, i.e. how to prevent progression and exacerbation of the disorder, signs of progression, and consultation alternatives. The education program comprised 12 slides with narration and required 13 minutes to complete. The education program was delivered via the same internet website that was used for the questionnaire survey.

\subsection{Statistical analysis}

All analyses were performed using the Statistical Package for the Social Sciences (SPSS) version 16.0. McNemar's test was used to compare paired data, i.e., the results of the first and second questionnaires for each respondent. The chi-square test was used to compare both the characteristics of those seeking non-medical help and several demographic characteristics. Differences in rates between groups were assessed with the Bonferroni multiple comparison procedure. All statistical tests were 2-tailed and statistical significance was defined as a $\mathrm{P}$ value less than 0.05 .

\section{Results}

\subsection{Characteristics of participants}

The participants where 2690 parents of junior and senior high school students in Japan, 2465 of whom finished both questionnaires. Mean age \pm SD was $45.9 \pm 4.7$ years. A total of $2552(94.9 \%)$ respondents reported being married. Most (51.0\%) respondents were employed full-time. The detailed characteristics of the respondents have been previously described (Yoshii et al., 2011).

\subsection{Medical help-seeking behavior among parents of junior and senior high school students}

Table 1 shows the rate of help-seeking behavior, by type of consultation, reported on the questionnaires given before and after the education program. The most frequent (33.1\%-50.0\%) type of consultation selected by participants was one at a department of psychosomatic medicine. Only $6.5 \%$ to $17.3 \%$ of participants with children who had the 4 investigated symptoms chose to have a consultation in a mental hospital. The rate of parents seeking help was similar among those with children who showed all 3 symptoms and those with children who showed strange behavior. Thus, strange behavior was the conclusive factor in seeking medical help.

The same questionnaire was administered to the participants 1 week after they had viewed the education program on the website. The rates of those who reported seeking a consultation at a psychiatric clinic for children with social withdrawal or all 3 symptoms were significantly higher as compared with the first questionnaire ( $\mathrm{p}<0.05$ for all comparisons).

\subsection{Timing of medical help-seeking behavior}

For almost all symptom categories, approximately half (43.7\%-55.5\%) of participants sought help approximately 1 month after symptom onset (Table 1). About $80 \%$ of participants sought medical help within approximately 1 month for children with any symptom. Only $1.4 \%$ to $2.2 \%$ of participants waited longer than 1 year to seek help for a child with any symptom.

After the education program, the rate of participants who sought help within 1 week was significantly higher $(\mathrm{p}=0.001)$, as compared with the first questionnaire, for all symptom categories except sleeplessness. Those who reported waiting approximately half a year to seek help decreased for all symptom categories $(\mathrm{p}<0.05)$.

\subsection{Factors that predicted a decision not to seek psychiatric medical help}

Characteristics that predicted a decision not to seek psychiatric medical help (excepting consultation at a department of internal medicine) were having children with all 3 symptoms, age, and family income $(\mathrm{p}<0.05)$ (Table 2). Younger parents were less likely to seek psychiatric medical help. Among parents aged 30 to 39 years, $43.9 \%$ did not seek psychiatric medical help. The Bonferroni multiple comparison procedure showed significant differences in the rate between parents aged 30 to 39 years and both those aged 40 to 49 years $(\mathrm{p}=0.003)$ and those aged 50 to 59 years $(\mathrm{p}=0.001)$. In addition, $51.2 \%$ of respondents with a family income less than 11000 US dollars not seek psychiatric medical help. A lower family income was associated with not seeking psychiatric medical help. The Bonferroni multiple comparison procedure showed significant differences in the rate between parents with a family income of 32000 to 53000 US dollars and those with an income greater than 110000 US dollars $(\mathrm{P}<0.05)$.

\subsection{School help-seeking behavior among parents of junior and senior high school students}

Consultation with a homeroom teacher was the most frequent (13.9\%-41.4\%) school-based help-seeking 
behavior (Table 1), and consultation with the school nurse was the least frequent (8.5\%-12.5\%) school-based help-seeking behavior. After the education program, all school-based consultations were significantly more frequent as compared with responses to the first questionnaire ( $\mathrm{p}<0.05$ for all comparisons).

\section{Discussion}

Singh et al. (2006) reported that demographic factors associated with longer delays in help-seeking were being single, being unemployed, living alone, living in public housing, and ethnic minority status. Another study reported that patients with schizophrenia might not be fully aware that their condition is deteriorating. In addition, they noted that patients living alone tended to be slower to seek a mental health consultation (Koichi et al., 2009). These findings suggest that parents can play an important role in identifying symptoms of schizophrenia in their children, in whom they are well equipped to notice subtle changes. By identifying schizophrenia at an early stage, parents can reduce the time from onset of symptoms to start of treatment, which is important in improving QOL after treatment (Chong et al., 2004). However, parents of junior and senior high school students sometimes might do not seek help when a child has signs of schizophrenia.

Help-seeking among parents has been studied in many countries. One study investigated 34 parents with children aged 2-15 years in London (Sayal et al., 2010), another study enrolled African American mothers (mean age \pm SD of children: $14 \pm 0.8)$ in rural Georgia $(n=163)$ (Murry et al., 2011), and a Canadian report studied 506 parents of children aged 4-17 years (Reid et al., 2011). However, our study differed from those earlier investigations because it targeted parents of junior and senior high school students, because the gender and regional distributions of our sample were almost identical to those of the Japanese general population, and because the present study had a reliable, large sample size $(n=2690)$. In addition, to our knowledge, no other study has investigated the effectiveness of a web-based education program that aimed to improve help-seeking behavior among Japanese parents of adolescents. Studies of help-seeking have not yielded consistent results with regard to sex-based, socioeconomic, and ethnic determinants of behavior or the impact of such behavior on treatment delays (Anderson et al., 2010). Help-seeking may differ due to the nature of available medical care, the economy, and/or culture. Our study is therefore important.

We hypothesized that most parents of junior and senior high school students would consult departments of internal medicine. To test this hypothesis, we investigated help-seeking by inquiring about a nonspecific symptom of schizophrenia (sleeplessness), a prodromal symptom (social withdrawal), and a symptom of schizophrenia (strange behavior). We found that the most common (33.1\%-50.0\%) form of consultation for all symptom categories was at a department of psychosomatic medicine, a field that is concerned with the diagnosis and treatment of medical diseases and their related psychosocial factors, e.g., essential hypertension and arrhythmia, gastric and duodenal ulcer, bronchial asthma, diabetes mellitus, and migraine. Individuals with mental illnesses can be successfully treated in such departments in Japan. These results disagree with those of Jorm et al. (2007), who showed that Australian parents $(\mathrm{n}=2005)$ of children aged $12-25$ years did not universally recognize the potential value of seeking help from mental health professionals.

In the Australian study, parents frequently mentioned general practitioners (GPs) as an intended source of help for their children when asked questions after vignettes portraying either depression, depression with alcohol misuse, social phobia, or psychosis (Jorm et al., 2007). Our results disagree with those findings. In the present study, $21.6 \%$ of parents with a child who had a nonspecific symptom of schizophrenia (sleeplessness) and $2.7 \%$ of those with a child who had a prodromal symptom (social withdrawal) sought help at a department of internal medicine, which is similar to seeking treatment at a GP. The Japanese medical system permits easy access to specialists. Therefore, patients and their family do not usually have a stable family doctor and can freely seek specialist medical area care.

Our study showed that about $80 \%$ of parents of children with symptoms consult a doctor within 1 month of onset. This result differs from a logistic study in Canada (Czuchta et al., 2001), which showed that a mean of 7.33 months elapsed before parents $(n=20)$ sought psychiatric help (including help from either a family doctor, a psychiatrist, or a psychologist). Delays in seeking help can negatively affect the course and treatment of schizophrenia (Waddington et al., 1995; Wyatt, et al. 1997; Marshall et al., 2005). Patients may experience such delays in treatment if their parents do not initially consult a medical doctor.

Provision of psychiatric treatment-seeking behavior has been assessed throughout the world (Joa et al., 2008; Tanaka et al., 2003). For example, a Norwegian study showed that an early intervention program reduced DUP in first-episode schizophrenia from 16 to 5 weeks in a health care setting. The program used a combination of easy-access detection teams (DTs) and a massive information campaign (IC) on the signs and symptoms of psychosis (Joa et al., 2008). A previous study in Japan found that an education program significantly improved psychiatric treatment-seeking behavior among workers $(\mathrm{p}<0.05)$ (Tanaka et al., 2003). However, the time 
required in that study was much longer than in our program. In addition, that study did not target parents of junior and senior high school students.

Nicola et al. found that accessing information on the internet was associated with increased use of any mental health service, GPs, and mental health professionals (MHPs) (Reavley et al., 2010). Thus, there is evidence that internet-based therapy programs are an effective means of mental health service delivery (Griffiths et al., 2007). Our education program can be viewed over the internet in 13 minutes, which is likely to be more attractive to busy parents in Japan.

\section{Conclusions}

Many parents consulted a physician in a department of psychosomatic medicine when their child experienced symptoms of mental illness. Our web-based education program was useful in promoting medical help-seeking behavior among parents of junior and senior high school students in Japan.

\section{Acknowledgements and Funding}

The authors thank the study participants. This work was supported by a 2010 Grant-in-Aid for Scientific Research (C) from the Japan Society for the Promotion of Science (22592581), entitled Investigations of the Consciousness of Parents of Junior and Senior High School Students Concerning Schizophrenia and the Development of Educational Enlightenment Media.

\section{References}

Anderson, K. K., Fuhrer, R., \& Malla, A. K. (2010). The pathways to mental health care of first-episode psychosis patients: a systematic review. Psychological medicine, 40, 1585-97. http://dx.doi.org/10.1017\%2FS0033291710000371

Bechard-Evans, L., Schmitz, N., Abadi, S., et al. (2007). Determinants of help-seeking and system related components of delay in the treatment of first-episode psychosis. Schizophr Res., 96, 206-214. http://dx.doi.org/10.1016\%2Fj.schres.2007.07.017

Boydell, K. M., Gladstone, B. M., \& Volpe, T. (2006). Understanding help seeking delay in the prodrome to first episode psychosis: a secondary analysis of the perspectives of young people. Psychiatric Rehabilitation journal, 30, 54-60. http://dx.doi.org/10.2975\%2F30.2006.54.60

Chong, S. A., Lee, C., Bird, L., et al. (2004). A risk reduction approach for schizophrenia: the early psychosis intervention programme. Ann Acad Med Singapore, 33, 630-635.

Compton, M. T., Chien, V. H., Leiner, A. S., et al. (2008). Mode of onset of psychosis and family involvement in help-seeking as determinants of duration of untreated psychosis. Soc Psychiatry Psychiatr Epidemiol, 43, 975-82. http://dx.doi.org/10.1007\%2Fs00127-008-0397-y

Czuchta, D. M. \& McCay, E. (2001). Help-seeking for parents of individuals experiencing a first episode of schizophrenia. Arch Psychiatr Nurs., 15, 159-70. http://dx.doi.org/10.1053\%2Fapnu.2001.25415

Griffiths, K. M. \& Christensen, H. (2007). Internet-based mental health programs: A powerful tool in the rural medical kit. Australian Journal of Rural Health, 15, 81-87. http://dx.doi.org/10.1111\%2Fj.1440-1584.2007.008 59.x

Helgason, L. (1990). Twenty years' follow-up of first psychiatric presentation for schizophrenia: what could have been prevented? Acta Psychiatr Scand., 81, 231-235. http://dx.doi.org/10.1111/j.1600-0447.1990.tb06486.x

Joa, I., Johannessen, J. O., Auestad, B., et al. (2008). The Key to Reducing Duration of Untreated First Psychosis: Information Campaigns. Schizophr Bull., 34, 466-472. http://dx.doi.org/10.1093\%2Fschbul\%2Fsbm 095

Jorm, A. F., Wright, A., \& Morgan, A. J. (2007). Beliefs about appropriate first aid for young people with mental disorders: findings from an Australian national survey of youth and parents. Early Intervention in Psychiatry, 1, 61-70. http://dx.doi.org/10.1111\%2Fj.1751-7893.2007.00012.x

Jorm, A. F., Wright, A., \& Morgan, A. J. (2007). Where to seek help for a mental disorder? National survey of the beliefs of Australian youth and their parents. Med J Aust., 187, 556-60.

Kessler, R. C., Berglund, P., Demler, O., et al. (2005). Lifetime prevalence and age-of-onset distributions of DSM-IV disorders in the national comorbidity survey replication. Arch Gen Psychiatry, 62, 593-602. http://dx.doi.org/10.1001\%2Farchpsyc.62.6.593

Koichi, R., Miyamoto, Y., Akiyama, M., et al. (2009). Awareness of early warning signs and help-seeking behaviors among patients with schizophrenia who utilize social rehabilitation facilities in Japan. $J$ Psychiatr 
Ment Health Nurs., 16, 694-702. http://dx.doi.org/10.1111\%2Fj.1365-2850.2009.01450.x

Larsen, T. K., Johannessen, J. O., \& Opjordsmoen, S. (1998). First-episode schizophrenia with long duration of untreated psychosis. Br J Psychiatry, 172, 45-52.

Lincoln, C. V. \& McGorry, P. (1995). Who cares? Pathways to psychiatric care for young people experiencing a first episode of psychosis. Psychiatric Serv., 46, 1166-1171.

Loebel, A. D., Lieberman, J. A., Alvir, J. M., et al. (1992). Duration of psychosis and outcome in first-episode schizophrenia. Am J Psychiatry, 149, 1183-1188.

Marshall, M., Lewis, S., Lockwood, A., et al. (2005). Association between duration of untreated psychosis and outcome in cohorts of first-episode patients: a systematic review. Arch Gen Psychiatry Ep., 62, 975- 83. http://dx.doi.org/10.1001\%2Farchpsyc.62.9.975

Murry, V. M., Heflinger, C. A., Suiter, S. V., et al. (2011). Examining Perceptions About Mental Health Care and Help-Seeking Among Rural African American Families of Adolescents. J Youth Adolesc., 40, 1118-31. http://dx.doi.org/10.1007\%2Fs10964-010-9627-1

Nishida, A., Tanii, H., Nishimura, Y., et al. (2008). Associations between psychotic-like experiences and mental health status and other psychopathologies among Japanese early teens. Schizophr Res., 99, 125-133. http://dx.doi.org/10.1016\%2Fj.schres.2007.11.038

O'Callaghan, E., Turner, N., Renwick, L., et al. (2010). First episode psychosis and the trail to secondary care: help-seeking and health-system delays. Soc Psychiatry Psychiatr Epidemiol, 45, 381-91. http://dx.doi.org/10.1007\%2Fs00127-009-0081-x

Perkins, D. O., Gu, H., Boteva, K., et al. (2005). Relationship between duration of untreated psychosis and outcome in first-episode schizophrenia: a critical review and meta-analysis. Am J Psychiatry, 162, 1785-1804. http://dx.doi.org/10.1176\%2Fappi.ajp.162.10.1785

Platz, C., Umbricht, D. S., Cattapan-Ludewig, K., et al. (2006). Help-seeking pathways in early psychosis. Soc Psychiatry Psychiatr Epidemiol, 41, 967-974. http://dx.doi.org/10.1007\%2Fs00127-006-0117-4

Reavley, N. J., Cvetkovski, S., \& Jorm, A. F. (2011). Sources of information about mental health and links to help seeking: findings from the 2007 Australian National Survey of Mental Health and Wellbeing. Soc Psychiatry Psychiatr Epidemiol, 46, 1267-74. http://dx.doi.org/10.1007\%2Fs00127-010-0301-4

Reid, G. J., Cunningham, C. E., Tobon, J. I., et al. (2011). Help-Seeking for Children with Mental Health Problems: Parents' Efforts and Experiences. Adm Policy MentHealth, 38, 384-97. http://dx.doi.org/10.1007/s10488-010-0325-9

Sayal, K., Tischler, V., Coope, C., et al. (2010). Parental help-seeking in primary care for child and adolescent mental health concerns: qualitative study. $\operatorname{Br} J \quad$ Psychiatry, 197, 476-81. http://dx.doi.org/10.1192\%2Fbjp.bp. 110.081448

Singh, S. P. \& Grange, T. (2006). Measuring pathways to care in first-episode psychosis: A systematic review. Schizophrenia Research, 81, 75-82. http://dx.doi.org/10.1016\%2Fj.schres.2005.09.018

Tanaka, G., Ogawa, T., Inadomi, H., et al. (2003). Effects of an education program on public attitudes towards mental illness. Psychiatry Clin Neurosci, 57, 595-602. http://dx.doi.org/10.1046\%2Fj.1440-1819.2003.01173.x

Unal, S., Kaya, B., \& Yalvaç, H. D. (2007). Patients' explanation models for their illness and help-seeking behavior. Turkish Journal of Psychiatry, 18, 38-47.

Van, O. J. \& Delespaul, P. (2005). Toward a world consensus on prevention of schizophrenia. Dialogues Clin Neurosci., 7, 53-67.

Waddington, J. L., Youssef, H. A., \& Kinsella, A. (1995). Sequential cross-sectional and 10-year prospective study of severe negative symptoms in relation to duration of initially untreated psychosis in chronic schizophrenia. Psychol Med., 25, 849-57. http://dx.doi.org/10.1017\%2FS0033291700035108

Wyatt, R. J., Green, M. F., \& Tuma, A. H. (1997). Long-term morbidity associated with delayed treatment of first admission schizophrenic patients: a re-analysis of the Camarillo State Hospital data. Psychol Med., 27, 261-8. http://dx.doi.org/10.1017\%2FS0033291796004345

Yoshii, H., Watanabe, Y., Kitamura, H., et al. (2011). Effect of an education program on improving knowledge of schizophrenia among parents of junior and senior high school students in Japan. BMC Public Health, 11, 323. http://dx.doi.org/10.1186\%2F1471-2458-11-323 
Table 1. Rate (\%) of help-seeking among parents of junior and senior high school students

\begin{tabular}{|c|c|c|c|c|c|c|c|c|c|c|c|c|}
\hline & \multicolumn{3}{|c|}{ Sleeplessness (A) } & \multicolumn{3}{|c|}{ Strange behavior (B) } & \multicolumn{3}{|c|}{ Social withdrawal (C) } & \multicolumn{3}{|c|}{$A, B$, and $C$} \\
\hline Type of consultation & First & $\begin{array}{l}\text { Seco } \\
\text { nd }\end{array}$ & $\mathrm{p}^{*}$ & First & $\begin{array}{l}\text { Seco } \\
\text { nd }\end{array}$ & $\mathrm{p}^{*}$ & First & $\begin{array}{l}\text { Seco } \\
\text { nd }\end{array}$ & $\mathrm{p}^{*}$ & First & $\begin{array}{l}\text { Seco } \\
\text { nd }\end{array}$ & $\mathrm{p}^{*}$ \\
\hline \multicolumn{13}{|l|}{ Medical } \\
\hline Mental hospital & 6.5 & 6.8 & 0.822 & 14.2 & 14.2 & 0.717 & 8.7 & 8.9 & 1.000 & 17.3 & 17.8 & 0.941 \\
\hline Psychiatric clinic & 13 & 13.8 & 0.592 & 24.1 & 26.8 & 0.051 & 15.9 & 18.6 & 0.017 & 27.4 & 31.4 & 0.003 \\
\hline $\begin{array}{l}\text { Department of } \\
\text { psychosomatic } \\
\text { medicine }\end{array}$ & 33.1 & 29.9 & 0.024 & 45.2 & 43.3 & 0.319 & 35.1 & 36.0 & 0.532 & 50.0 & 51.0 & 0.313 \\
\hline $\begin{array}{l}\text { Department of internal } \\
\text { medicine }\end{array}$ & 21.6 & 17.3 & 0.001 & 5.9 & 5.7 & 0.952 & 2.7 & 2.8 & 0.931 & 5.5 & 5.1 & 0.609 \\
\hline \multicolumn{13}{|l|}{ School } \\
\hline Homeroom teacher & 13.9 & 19.8 & 0.001 & 23.6 & 31.2 & 0.001 & 41.4 & 45.4 & 0.001 & 29.0 & 35.0 & 0.001 \\
\hline School nurse & 8.5 & 13.4 & 0.001 & 10.8 & 16.4 & 0.001 & 12.5 & 19.3 & 0.001 & 11.5 & 18.7 & 0.001 \\
\hline School counselor & 10.5 & 13.8 & 0.001 & 16.5 & 21.7 & 0.001 & 27.5 & 30.3 & 0.011 & 20.9 & 26.1 & 0.001 \\
\hline \multicolumn{13}{|l|}{ Community } \\
\hline Health center & 1.9 & 2.7 & 0.055 & 2.8 & 4.8 & 0.001 & 2.1 & 4.1 & 0.001 & 3.1 & 5.6 & 0.001 \\
\hline Mental health center & 2.7 & 4.3 & 0.004 & 6.2 & 9.7 & 0.001 & 5.2 & 8.9 & 0.001 & 7.8 & 12.1 & 0.001 \\
\hline \multicolumn{13}{|l|}{ Other } \\
\hline Family circle & 53.6 & 61.2 & 0.001 & 49.9 & 56.8 & 0.001 & 51.8 & 57.5 & 0.001 & 48.7 & 54.9 & 0.001 \\
\hline Neighbor & 1.6 & 1.9 & 0.445 & 1.0 & 0.6 & 0.511 & 1.0 & 0.9 & 1.000 & 0.8 & 0.7 & 0.868 \\
\hline Classmate's parents & 6.6 & 7.6 & 0.058 & 4.6 & 4.6 & 0.632 & 6.7 & 6.5 & 0.813 & 4.5 & 4.2 & 0.944 \\
\hline Telephone consultation & 5.5 & 4.7 & 0.323 & 8.3 & 7.0 & 0.227 & 8.9 & 7.5 & 0.232 & 9.0 & 7.8 & 0.314 \\
\hline Internet consultation & 10.8 & 8.5 & 0.022 & 13.3 & 11.0 & 0.034 & 14.1 & 11.1 & 0.004 & 13.8 & 11.6 & 0.057 \\
\hline Needless treatment & 6.7 & 6.8 & 0.824 & 4.4 & 4.7 & 0.737 & 4.8 & 4.9 & 1.000 & 4.2 & 4.5 & 0.730 \\
\hline \multicolumn{13}{|l|}{$\begin{array}{l}\text { Timing of medical } \\
\text { help-seeking }\end{array}$} \\
\hline Within one week & 31.9 & 34 & 0.150 & 40.3 & 46.0 & 0.001 & 24.4 & 30.8 & 0.001 & 44.9 & 51.4 & 0.001 \\
\hline About 1 month later & 53.3 & 54.3 & 0.340 & 46.8 & 44.9 & 0.242 & 55.5 & 54.8 & 0.688 & 43.7 & 39.9 & 0.012 \\
\hline About half a year later & 7.5 & 5.8 & 0.011 & 8.3 & 5.5 & 0.001 & 13.2 & 9.4 & 0.001 & 7.1 & 4.8 & 0.001 \\
\hline More than 1 year later & 1.8 & 1.1 & 0.042 & 1.4 & 0.9 & 0.149 & 2.2 & 1.7 & 0.358 & 1.5 & 1.4 & 1.000 \\
\hline $\begin{array}{l}\text { Non-medical help } \\
\text { sought }\end{array}$ & 5.5 & 4.9 & 0.228 & 3.2 & 2.6 & 0.132 & 4.7 & 3.2 & 0.005 & 2.9 & 2.5 & 0.294 \\
\hline
\end{tabular}


Table 2. Associations between parental characteristic and a decision not to seek medical help for children with sleeplessness, strange behavior, and social withdrawal

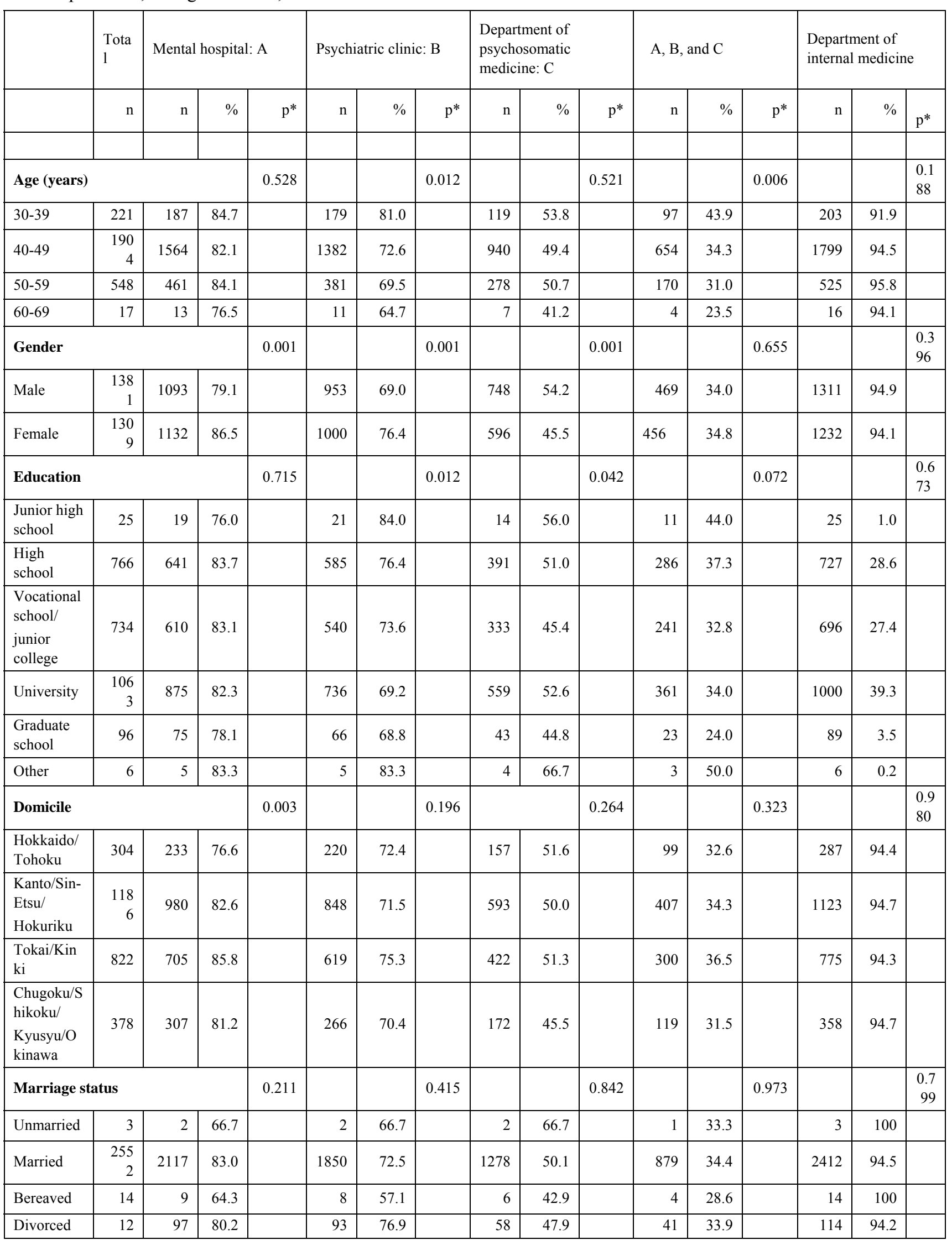




\begin{tabular}{|c|c|c|c|c|c|c|c|c|c|c|c|c|c|c|c|c|}
\hline \multicolumn{4}{|c|}{ Family structure } & \multirow[t]{2}{*}{0.635} & \multirow[b]{2}{*}{1523} & \multirow[b]{2}{*}{72.8} & \multirow[t]{2}{*}{0.837} & \multirow[b]{2}{*}{1053} & \multirow[b]{2}{*}{50.3} & \multirow[t]{2}{*}{0.661} & \multirow[b]{2}{*}{723} & \multirow[b]{2}{*}{34.6} & \multirow[t]{2}{*}{0.759} & \multirow[b]{2}{*}{1976} & \multirow[b]{2}{*}{94.5} & \multirow[t]{2}{*}{$\begin{array}{r}0.9 \\
82\end{array}$} \\
\hline 2 parents & $\begin{array}{r}209 \\
2\end{array}$ & 1738 & 83.1 & & & & & & & & & & & & & \\
\hline 1 parent & 89 & 70 & 78.7 & & 65 & 73.0 & & 40 & 44.9 & & 26 & 29.2 & & 84 & 94.4 & \\
\hline $\begin{array}{l}3 \\
\text { generation } \\
\mathrm{s}\end{array}$ & 466 & 383 & 82.2 & & 332 & 71.2 & & 232 & 49.8 & & 162 & 34.8 & & 442 & 94.8 & \\
\hline Other & 43 & 34 & 79.1 & & 33 & 76.7 & & 19 & 44.2 & & 14 & 32.6 & & 41 & 95.3 & \\
\hline \multicolumn{4}{|c|}{ Employment } & 0.001 & & & 0.006 & & & 0.002 & & & 0.283 & & & $\begin{array}{r}0.7 \\
77\end{array}$ \\
\hline Full-time & $\begin{array}{r}137 \\
3\end{array}$ & 1091 & 79.5 & & 960 & 69.9 & & 726 & 52.9 & & 458 & 33.4 & & 1298 & 94.5 & \\
\hline Part-time & 471 & 409 & 86.8 & & 360 & 76.4 & & 205 & 43.5 & & 152 & 32.3 & & 449 & 95.3 & \\
\hline $\begin{array}{l}\text { Self-emplo } \\
\text { yed }\end{array}$ & 259 & 211 & 81.5 & & 186 & 71.8 & & 137 & 52.9 & & 99 & 38.2 & & 241 & 93.1 & \\
\hline $\begin{array}{l}\text { Full-time } \\
\text { housewife }\end{array}$ & 542 & 480 & 88.6 & & 417 & 76.9 & & 251 & 46.3 & & 201 & 37.1 & & 512 & 94.5 & \\
\hline $\begin{array}{l}\text { Unemploy } \\
\text { ed }\end{array}$ & 45 & 34 & 75.6 & & 30 & 66.7 & & 25 & 55.6 & & 15 & 33.3 & & 43 & 95.6 & \\
\hline \multicolumn{4}{|l|}{ Occupation } & 0.535 & & & 0.877 & & & 0.003 & & & 0.154 & & & $\begin{array}{l}0.6 \\
08\end{array}$ \\
\hline $\begin{array}{l}\text { Agricultur } \\
\text { e and } \\
\text { forestry }\end{array}$ & 11 & 10 & 90.9 & & 8 & 72.7 & & 7 & 63.6 & & 5 & 45.5 & & 11 & 100 & \\
\hline $\begin{array}{l}\text { Production } \\
\text { labor } \\
\text { service and } \\
\text { transportati } \\
\text { on and } \\
\text { communic } \\
\text { ation }\end{array}$ & 772 & 624 & 80.8 & & 556 & 72.0 & & 424 & 54.9 & & 286 & 37.0 & & 729 & 94.4 & \\
\hline $\begin{array}{l}\text { Sales and } \\
\text { marketing } \\
\text { and service } \\
\text { industry }\end{array}$ & 160 & 134 & 83.8 & & 114 & 71.3 & & 65 & 40.6 & & 44 & 27.5 & & 148 & 92.5 & \\
\hline $\begin{array}{l}\text { Profession } \\
\text { als }\end{array}$ & 689 & 574 & 83.3 & & 511 & 74.0 & & 340 & 49.3 & & 233 & 33.8 & & 649 & 94.2 & \\
\hline Other & $\begin{array}{r}105 \\
8\end{array}$ & 883 & 83.5 & & 764 & 72.2 & & 508 & 48.0 & & 357 & 33.7 & & 1006 & 95.1 & \\
\hline \multicolumn{4}{|c|}{ Family income, (US dollars) } & 0.828 & & & 0.103 & & & 0.020 & & & 0.002 & & & $\begin{array}{l}0.1 \\
99\end{array}$ \\
\hline$<11000$ & 41 & 36 & 87.8 & & 33 & 80.5 & & 22 & 53.7 & & 21 & 51.2 & & 36 & 87.8 & \\
\hline $\begin{array}{l}11000-320 \\
00\end{array}$ & 196 & 160 & 81.6 & & 146 & 74.5 & & 98 & 50.0 & & 74 & 37.8 & & 189 & 96.4 & \\
\hline $\begin{array}{l}32000-530 \\
00\end{array}$ & 502 & 421 & 83.9 & & 377 & 75.1 & & 284 & 56.6 & & 198 & 39.4 & & 476 & 94.8 & \\
\hline $\begin{array}{l}53000-110 \\
000\end{array}$ & $\begin{array}{r}146 \\
5\end{array}$ & 1208 & 82.5 & & 1065 & 72.7 & & 710 & 48.5 & & 485 & 33.1 & & 1379 & 94.1 & \\
\hline$>110000$ & 486 & 400 & 82.3 & & 332 & 68.3 & & 230 & 47.3 & & 147 & 30.2 & & 463 & 95.3 & \\
\hline
\end{tabular}

* The chi-square test 